\title{
Trafik Gürültüsünün Kontrolünde Bitki Perdelerinden Yararlanılması Üzerine Bir Araştırma
}

\section{Neslihan DOYGUN1 $1^{\infty}$ (D) Hakan DOYGUN2 \\ ${ }^{1}$ KSU Orman Fakültesi Peyzaj Mimarlığı Bölümü, ${ }^{2}$ İzmir Demokrasi Üniversitesi Mimarlık Fakültesi Peyzaj Mimarlığı Bölümü \\ $\bowtie$ : nesdoy@ksu.edu.tr}

\section{ÖZET}

$\mathrm{Bu}$ çalışma, trafik gürültüsünün kontrolünde bitki türlerinden perdeleme elemanı olarak yararlanma olanaklarını incelemek amacıyla gerçekleştirilmiştir. Kahramanmaraş Sütçü Imam Üniversitesi Avşar Yerleşkesi'nde gerçekleştirilen ölçümler kapsamında, bitki perdelerinin oluşturulmasında 7 farklı ağaççık ve çalı formlu dış mekan süs bitki türü kullanılmıştır. Bitki perdelerinde öncelikli olarak türlere tek başlarına yer verilmiş, ardından türler arasında bazı kombinasyonlar denenerek boy ve form farklılaşmasının gürültüyü perdeleme üzerindeki etkileri incelenmeye çalışılmıştır. Elde edilen sonuçlar, bitki perdelerinin gürültü düzeyinin azaltılmasında etkin rol oynadığını ortaya koymuştur. Çalışma kapsamında uygulanan yöntemlerin ve ortaya konulan bulguların, benzer bilimsel araştırmalara ve çevre sorunlarının insanlar üzerindeki etkilerinin azaltılmasına yönelik uygulamalara katkı sağlaması beklenmektedir.

\section{A Research on the Use of Vegetation Barriers in Traffic Noise Control}

DOI:10.18016/ ksudobil.369519

\author{
Makale Tarihçesi \\ Received : 21.12.2017 \\ Accepted : 06.03.2018
}

Anahtar Kelimeler Gürültü kirlenmesi, gürültü perdesi, bitki perdeleri, çevre koruma

\section{Araştırma Makalesi}

\section{ABSTRACT}

This study was conducted to investigate the opportunities of the use of vegetation barriers in traffic noise control. Based on the measurements taken at The University of Kahramanmaraş Sütçü İmam Avşar Campus, 7 different exotic shrubs species have been used to establish vegetation barriers. While configuring vegetation barriers, in the first hand, the species have been assessed singly, and then, some combinations have been experienced to see the effects of altitude, and forms on the effectiveness of the vegetation barriers. The results have shown that shrubs species play an important role to decrease the noise levels. It is expected that the methods and the results could guide similar scientific studies and applications

\section{Article History}

Geliş : 21.12.2017

Kabul : 06.03.2018

\author{
Keywords \\ Noise pollution, \\ noise barrier, \\ vegetation barrier, \\ environmental protection
}

\section{Research Article}

To Cite : Doygun N Doygun H 2018. Trafik Gürültüsünün Kontrolünde Bitki Perdelerinden Yararlanılması Üzerine Bir Araştırma. KSÜ Tarim ve Doğa Derg 21(4):599-606, 2018. DOI:10.18016/ ksudobil.369519

\section{GiRiş}

Gürültü kirliliği, yerleşim alanlarında halk sağlığını ve yaşam kalitesini olumsuz yönde etkileyen giderek artan bir çevre sorunu olarak değerlendirilmekte (WHO, 2012; Bayramoğlu ve ark., 2014; Akay, 2015; Doygun, 2016), uzun süre maruz kalınması halinde fizyolojik ve psikolojik rahatsızlıklara neden olmaktadır (Anonymous, 2009a; Morova ve ark., 2010). Özellikle ulaşım güzergâhları ve yoğun nüfusa sahip yerleşim alanlarında yaygın şikayetlere neden olan gürültü kirliliği, $55 \mathrm{~dB}(\mathrm{~A})$ üzerinde bir seviyeye maruz kalınması halinde huzursuzluk şikayetlerine yol açarken, $65 \mathrm{~dB}(\mathrm{~A})$ üzerinde ise kardiyovasküler rahatsılıklar söz konusu olmaktadır (Stanners and Bourdeau, 1995; Anonymous, 2009a).
Gürültünün insanlar ve yaşam konforu üzerindeki olumsuz etkilerini azaltmak ve sinırlandırmak amacıyla perdeleme nitelikli önleyici çalışmalar gerçekleştirilmektedir. Ancak özellikle kentsel çevrelerde trafik gürültüsünü önlemede kullanılan bariyerlerin (beton ve plastik duvarlar vb) yüksek maliyetleri ve estetik olmayan görünümleri nedeniyle, perdeleme çalışmalarında bitkilerden yararlanılması düşüncesi önemli bir alternatif olarak değerlendirilmektedir. Bitkilerin kent ekosistemini iyileştirici özelliklerinin yanı sıra çevrenin görsel, estetik ve rekreasyonel kalitesine yönelik sağladıkları katkılar da gürültü perdesi olarak tercih edilmelerinde önemli rol oynayan faktörler arasında yer almaktadır (Posada ve ark., 2009; Mutlu, 2010; Yeşil ve ark., 2015; Renterghem ve Botteldooren, 2016). 
$\mathrm{Bu}$ çalışmada, trafik gürültüsünün kontrolünde bazı ağaççık ve çalı formlu bitki türlerinden perdeleme elemanı olarak yararlanma olanaklarının incelenmesi amaçlanmıştır Çalışma kapsamında uygulanan yöntemlerin ve ortaya konulan bulguların, benzer bilimsel araştırmalara ve çevre sorunlarının insanlar üzerindeki etkilerinin azaltılmasına yönelik uygulamalara katkı sağlaması beklenmektedir.

\section{MATERYAL VE YÖNTEM}

\section{Bitki Perdeleri}

Bitki perdelerinin oluşturulmasında ağaç̧̧ı ve çalı formlu yedi farklı dış mekan süs bitkisi türü kullanılmıştır (Çizelge 1). Türlerin belirlenmesinde önceki çalışmalardan yararlanılmış (Ustasüleyman, 1998; Aktaş, 2002; Erdoğan ve Yazgan, 2007; Mutlu, 2010), ayrıca ülkemizde yaygın olarak yetişiyor ve kullanılıyor olma durumları göz önünde bulundurulmuştur. Türlerin farklı boy, form ve yaprak özelliklerine sahip olmalarına dikkat edilmiştir. Bitkiler her türden saksılı olarak 40'ar adet temin edilmiş olup, ideal formuna kavuşmuş bireylerin çalışmaya dahil edilmesine özen gösterilmiştir.

Bitki perdelerinin oluşturulmasında öncelikli olarak türler tek başlarına kullanılmış, ardından türler arasinda bazı kombinasyonlar denenerek boy ve form gibi özelliklerin gürültüyü perdeleme üzerindeki etkileri incelenmeye çalışılmıştır. Bitki perdeleri, her türe ait 40 adet bireyin, yan yana ayn hizada dizilmeleri ile oluşturulmuştur.

\section{Ölçüm Süreci}

Ölçüm yapılacak alanın çevresel diğer gürültü kaynaklarından arındırılmış olmasını sağlamak amacıyla, ölçüm çalışmaları Kahramanmaraş Sütçü İmam Üniversitesi Avşar Yerleşkesi'nde, araç trafiğinin veya herhangi diğer faaliyetin bulunmadiğ bir alanda, Pazar günü, kuvvetli rüzgâr ve yağış olmayan bir periyotta yerine getirilmiştir. Ölçümler boş bir otoparkta gerçekleştirilmiş olup, zemin kilit parke ile kaplıdır ve yakın çevrede sesin yankılanmasına veya absorbe edilmesine neden olacak herhangi bir yapı bulunmamaktadır (Şekil 1).Gürültü seviyelerinin ölçülmesinde Delta OHM HD2010 cihazı kullanılmıştır. Serbest alanda ölçümler için uygun yüksek stabilite ve duyarlıkta mikrofonu bulunan cihazın çalışma aralığı 20-140 dB(A)'dır. Saniyede 8 örnek alabilme, istenilen periyotta ve sürede ölçüm yapacak şekilde programlanabilme, otomatik kaydetme ve tripod ile sabitlenebilme özellikleri bulunan cihaz ile diş mekanda planlı ve düzenli çalışabilme olanağ bulunmaktadır (Anonymous, 2009b; Doygun, 2016).
Gürültü seviyeleri Leq değeri bakımından 3'er dakikalık periyotlar halinde ölçülmüş (Zannin et al., 2006; Zannin et al., 2013), cihaz 5 saniye aralıklarla kayıt yapacak şekilde programlanmıştır. Bu çalışma prensibine göre; gürültü ölçümü 3 dakika (180 sn) boyunca kesintisiz biçimde devam etmekte, her 5 saniyenin ortalaması otomatik olarak kaydedilmektedir. Böylelikle, cihazın bilgi depolama özelliğinden yararlanılarak, her ölçüm periyodu için 60 'ar adet değer elde edilmiştir. Bu değerlerin aritmetik ortalaması ise, o periyoda ait ortalama gürültü seviyesini vermektedir (Doygun, 2016). Cihaz, ölçümler süresince yerden $130 \mathrm{~cm}$ yükseklikte ve yer ile $45^{\circ}$ açı yapacak şekilde tripod üzerine sabitlenmiştir. Gürültü kaynağı olarak, 125 cc kapasiteli ve benzinli Kymco marka scooter tipinde bir motordan yararlanılmıştır.

Scooter, ölçümler süresince rölantide çalıştırılmıştır. Gürültü ölçüm çalışmalarında, bitki perdesi ortada ve ölçüm cihazı ile scooter ise perdenin her iki tarafında 4'er m uzakta olacak şekilde konumlandırılmışlardır. Bitkiler, otoparkı ikiye bölen tretuvarın gürültü ölçüm cihazı tarafına yerleştirilmiş, böylece saksıların gürültüyü önleme veya yönlendirme olasılığı elimine edilmiştir (Şekil 1 ve 2).

\section{BULGULAR}

Bitki perdelerinin gürültü kontrolündeki etkinliklerinin belirlenmesi çalışmasında öncelikle scooter motorun gürültü seviyesi belirlenmiştir. Rölantide çalışır durumdaki scooter'dan $8 \mathrm{~m}$ uzaklıkta, arada bitki perdesi olmadan 3 dakika süresince yapılan ölçüm sonucunda gürültü seviyesi $53 \mathrm{~dB}(\mathrm{~A})$ olarak belirlenmiştir.

Bitkiler ile yapılan ölçümlerde, öncelikle perdeler tek tür kullanılarak tesis edilmiştir. Dört tür için ayrı ayrı gerçekleştirilen ölçümler sonucunda gürültü seviyesinin $2,2-1,2 \quad \mathrm{~dB}(\mathrm{~A})$ aralığında azaldığ belirlenmiştir. Pittosporum tobira gürültü seviyesinin azaltılmasında en etkili tür olmuştur (Çizelge 2).

Bitki türleri arasında kombinasyonlar oluşturularak yapılan ölçümlerde, yükseklik kademelenmesinin gürültü kontrolü üzerindeki etkileri incelenmeye çalışılmıştır. Bu amaçla öncelikle, farklı boylara sahip üç tür kullanılarak, üç farklı yükseklik kademesi oluşturulmuştur. Elde edilen sonuçlar, iki sıra yapıldığında, bitki yükseklikleri arasındaki fark artmasına rağmen gürültü seviyesinin aynı düzeyde azaldığını göstermiştir (Şekil 3). Farklı yüksekliğe sahip üç tür ile kademelenme yapıldığında ise, iki tür ile yapılan sıraya göre, gürültü seviyesi $0,1 \mathrm{~dB}(\mathrm{~A})$ daha azalmıştır. 
Çizelge 1. Araştırmada kullanılan bitki türlerinin özellikleri

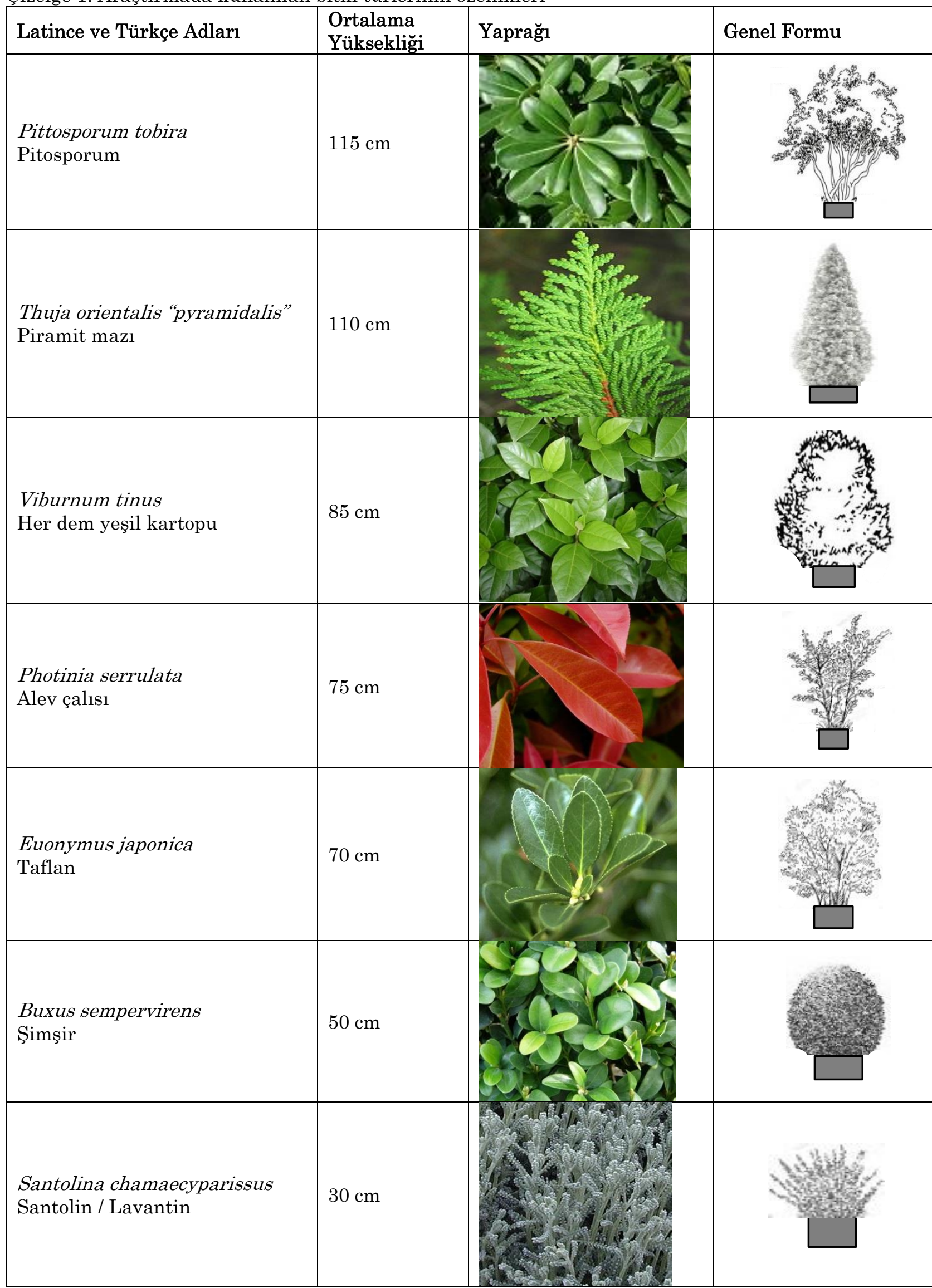




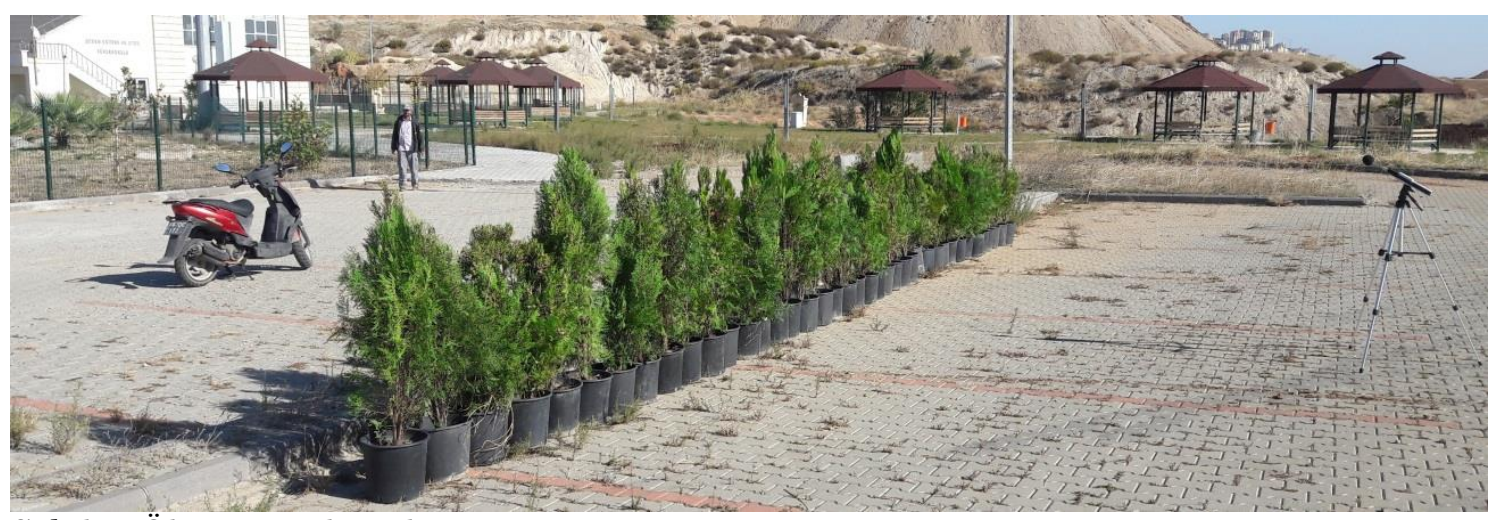

Şekil 1. Ölçüm yapılan alana ait görünüm

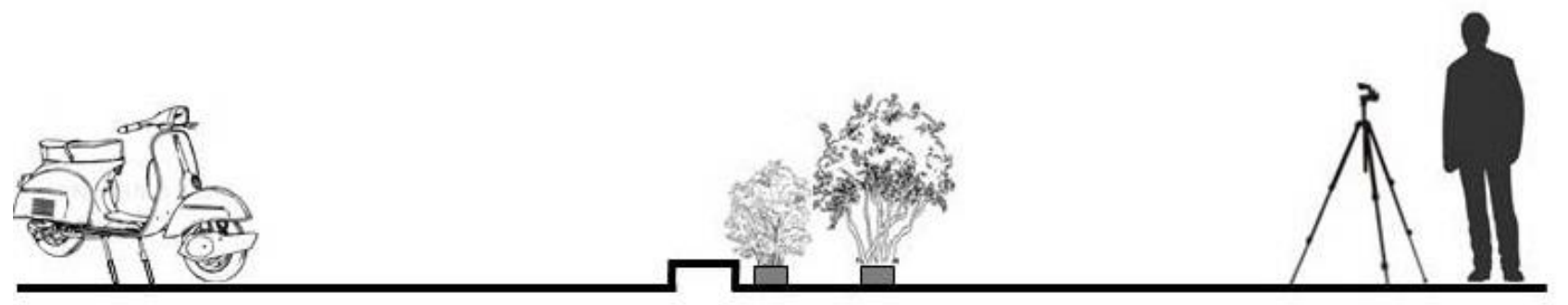

Şekil 2. Gürültü kaynağı, bitki perdesi ve ölçüm cihazının konumları

Bitki perdesindeki sıra sayısının artırılmasının gürültü kontrolü üzerindeki etkilerini incelemek amacıyla, tür sayısı artırılarak farklı ölçümler yapılmıştır. Bu amaçla, yükseklik kademelenmesi de gözetilerek beş türden meydana gelen bir perde oluşturulmuş ve ölçüm sonucunda 50,8 dB(A) değeri elde edilmiştir. Yani beş farklı tür ile meydana getirilen bitki perdesi, scooter'dan kaynaklanan gürültüyü $2,2 \quad \mathrm{~dB}(\mathrm{~A})$ düzeyinde azaltmıştır (Şekil 4).

Farklı kombinasyonlarda bitki perdelerinin oluşturulması kapsamında, Şekil 4'de verilen beşli bitki sirasina Thuja orientalis "pyramidalis" eklenerek altı sıradan meydana gelen bir perde tesis edilmiştir. $\mathrm{Bu}$ kombinasyon ile yapılan ölçümde, bitki perdesinin gürültüyü 2,5 $\mathrm{dB}(\mathrm{A})$ düzeyinde azalttığı belirlenmiştir (Şekil 5).
Yüksek bitki perdelerinin gürültü kontrolü üzerindeki etkilerini inceleyebilmek amacıyla, ölçüm cihazının yerden yükseliği azaltılarak farklı bir deneme yapılmıştır. Normal şartlarda yerden $130 \mathrm{~cm}$ yükseklikte olan ölçüm cihazı $90 \mathrm{~cm}$ seviyesine indirilmiş ve aynı bitki perdesi ile yapılan ölçümde gürültünün 3,5 dB(A) düzeyinde azaldığ görülmüştür (Şekil 5).

Bitki perdesi içerisinde tür değişiminin ölçüm sonuçları üzerindeki etkisini inceleyebilmek amacıyla, altı türden meydana gelen perde içerisindeki Photinia serrulata sırası çlkartılarak yerine Viburnum tinus sırası yerleştirilmiştir. Bu şekli ile yapılan ölçümde de aynı değere ulaşılmış, yani altılı perde içerisinde tür değişimi gerçekleştiğinde de gürültünün $2,5 \mathrm{~dB}(\mathrm{~A})$ düzeyinde azaldığı belirlenmiştir.

Çizelge 2. Tek tür ile oluşturulan perdelerle yapılan ölçümler

\begin{tabular}{|l|l|l|}
\hline Adı & $\begin{array}{l}\text { Ölçüm Değeri } \\
\mathrm{dB}(\mathrm{A})\end{array}$ & $\begin{array}{l}\text { Gürültüyü Azaltma Düzeyi } \\
\mathrm{dB}(\mathrm{A})\end{array}$ \\
\hline Pittosporum tobira & 50,8 & 2,2 \\
\hline Viburnum tinus & 51,4 & 1,6 \\
\hline Thuja orientalis "pyramidalis" & \multirow{2}{*}{51,8} & 1,2 \\
\hline Euonymus japonica & & \\
\hline
\end{tabular}




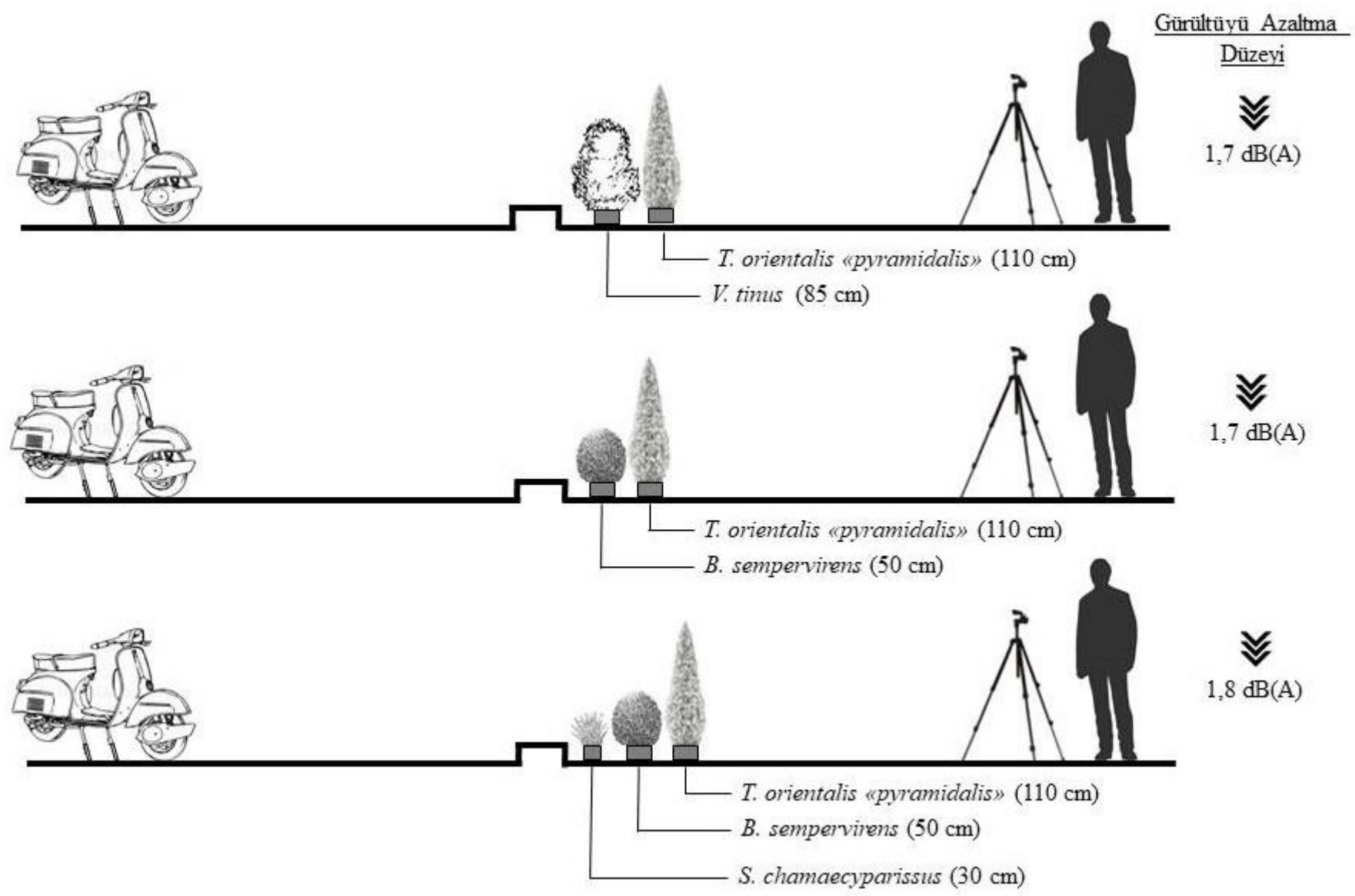

Şekil 3. Bitki perdesinde yükseklik kademelenmesinin gürültü üzerindeki etkisi

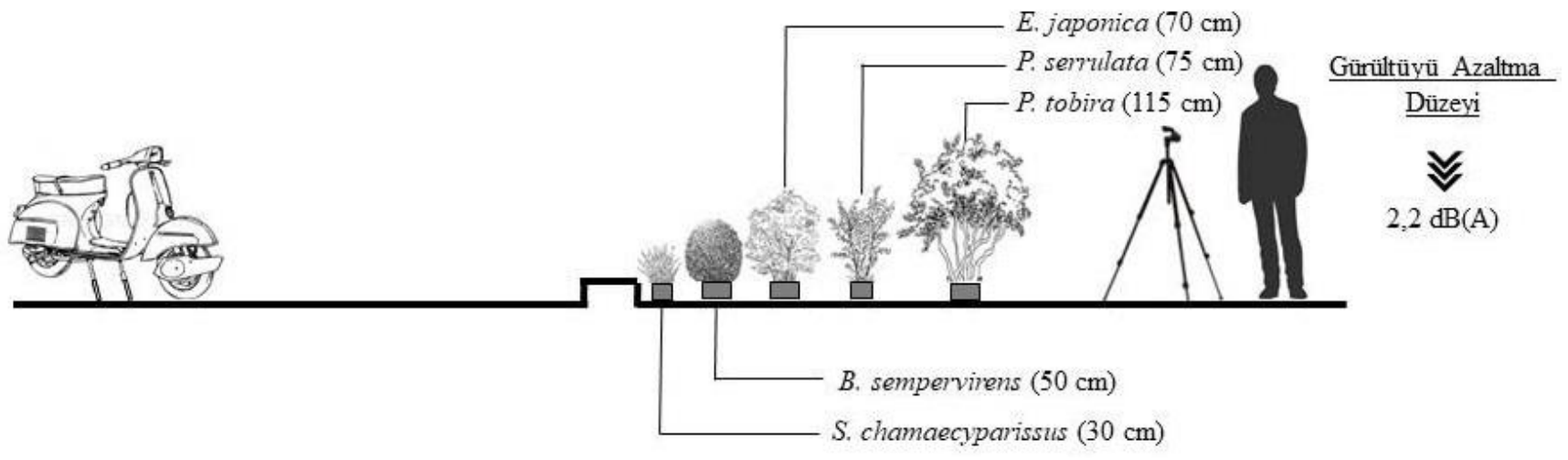

Şekil 4. Beş farklı tür ile oluşturulan bitki perdesine ait ölçüm

Bitki perdesinde farklı boylu türler kullanılarak gerçekleştirilen yükseklik kademelenmesinin gürültü kontrolü üzerindeki etkilerini incelemek amaciyla, altılı bitki perdesinin dizilimi değiştirilerek farklı bir deneme yapılmıştır (Şekil 6). Önceki denemelerde en alçak boylu bitki gürültü kaynağına doğru yer alıyorken, bu denemede en yüksek boylu olan tür gürültü kaynağının olduğu kısıma yerleştirilmiş, yani boy sırası tersine çevrilmiştir. Her iki sıralamada da aynı türler kullanılarak gerçekleştirilen bu denemede, bitki perdesinin gürültü düzeyini $3,8 \mathrm{~dB}(\mathrm{~A})$ azalttığg belirlenmiştir. Bu sonuç, yüksek boylu bitkinin gürültü kaynağına yakın konumlandırılması durumunda, gürültünün daha etkin biçimde kontrol edilebileceğini göstermektedir. 

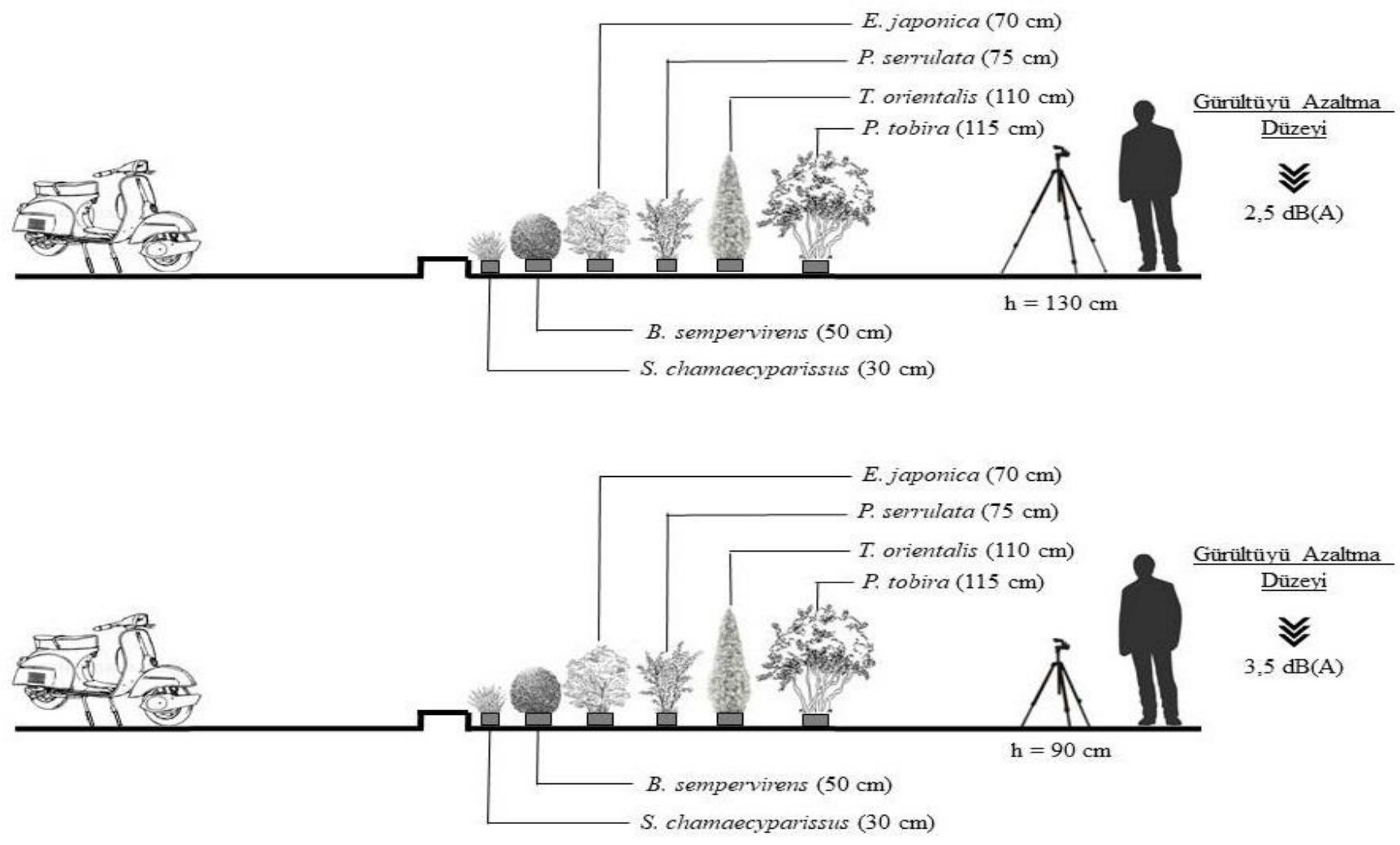

Şekil 5.Ölçüm cihazı yüksekliği değiştirilerek gerçekleştirilen ölçümler
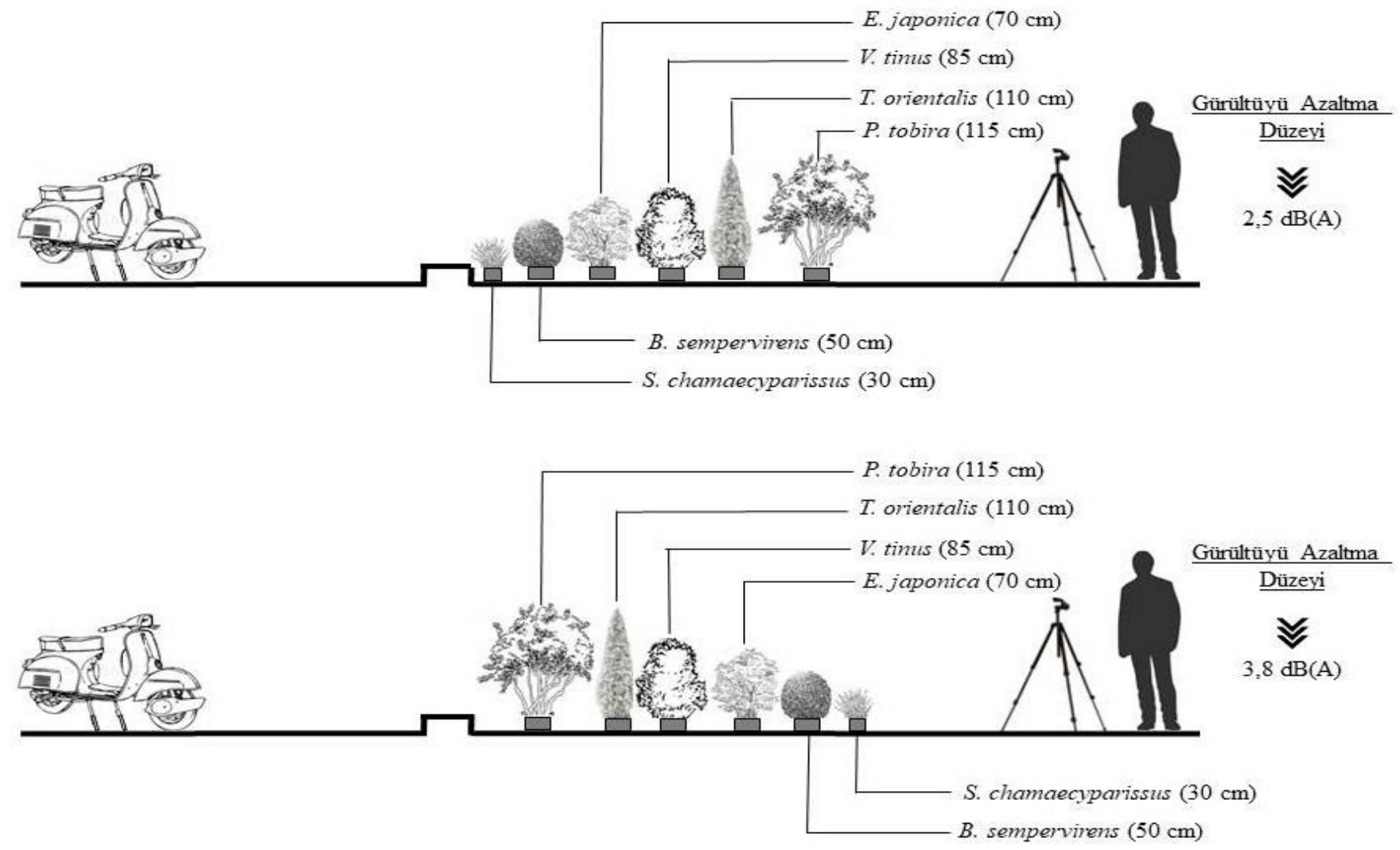

Şekil 6. Yükseklik kademelenmesi değiştirilerek gerçekleştirilen ölçümler 


\section{SONUÇLAR}

$\mathrm{Bu}$ çalışmada, trafik gürültüsünün kontrolünde bazı ağaççı ve çalı formlu bitki türlerinden perdeleme elemanı olarak yararlanma olanaklarının incelenmesi amaçlanmıştır.

Elde edilen sonuçlar, diğer araştırmalar ile benzer şekilde (Ustasüleyman, 1998; Aktaş, 2002; Erdoğan ve Yazgan, 2007; Mutlu, 2010), bitki perdelerinin gürültü kontrolünde etkin bir araç olarak kullanılabileceğini göstermiştir.

Tek başlarına veya farklı kombinasyonlarda kullanılmaları durumunda dahi, bu çalışmada değerlendirilen çalı ve ağaççı türü bitkiler gürültü düzeyinin azaltılmasında etkin rol oynamışlardır (Özer ve ark., 2008).

Çalışma ile elde edilen bulgulardan yola çıkılarak ulaşlan bazı değerlendirmeler ve öneriler, önceki benzer araştırmalara ait sonuçlar da göz önüne alınarak aşağıda özetlenmiştir:

Tek tür kullanılarak yapılan ölçümlerde Pittosporum tobira'nı en etkin sonucu vermesi; geniş yapraklı, gelişmiş ve geniş tepe taç yapisına sahip, yüksek boylu bitkilerin gürültü kontrolünde daha başarılı sonuçlar verebileceğine işaret etmektedir (Posada ve ark., 2009; Mutlu, 2010; Önder ve Koçbeker, 2012).

Pittosporum tobira ile hemen hemen ayn boya ve sık dokuya sahip olmakla birlikte, Thuja orientalis "pyramidalis"in gürültü düzeyini azaltmada daha az başarılı olmasının nedeninin, tepeye doğru daralan taç yapısı ve pulsu yaprak dokusu olduğu düşünülmektedir.

- Birden fazla tür ile tesis edilen bitki perdelerinde, gürültü kaynağından alıcıya doğru yükselen bir kademelenmenin oluşturulması, gürültü düzeyinin azaltılmasında önemli bir etki meydana getirmemiştir. Etkin bir perdeleme için, gürültü kaynağına yakın kesimde yüksek boylu bitki türlerine yer verilmesi gerektiği anlaşılmıştır.

Bitki perdesini meydana getiren sıra sayısının yani perde genişliğinin - artırılması gürültü düzeyinin azaltılmasında önemli rol oynamıştır (Erdoğan ve Yazgan, 2007; Kalansuriya ve ark., 2009; Önder ve Koçbeker, 2012).

Bitki perdesinin yüksek boylu bireylerden meydana getirilmesi, gürültü düzeyinin azaltılmasında önemli etkiye sahiptir.

Gürültü önleyici bitki perdelerinin oluşturulmasında, yörenin doğal bitki örtüsünde yer alan türlere yer verilmesi önerilmektedir. Çünkü doğal türler; çevre koşullarına kolay uyum sağlayabilmekte ve ideal gelişim özellikleri nedeniyle kendilerinden beklenen fiziksel performansları sergileyebilmektedirler (Erdoğan ve Yazgan, 2007; Önder ve Koçbeker, 2012)

- Bitki perdelerinin gürültü kontrolündeki rolünü belirlemede farklı bakış açıları geliştirmek ve farklı bitki türleri ile sınırsız sayıda kombinasyonlar deneyerek ölçümleri artırmak mümkündür. Bu çalışma kapsamında uygulanan yöntemler ve ortaya konulan bulgular, deneysel bir araştırma ürünü olup gelecekte gerçekleştirilecek benzer çalışmalara ışık tutma niteliği taşımaktadır. Çalışma ile ulaşılan sonuçların ve ortaya konulan değerlendirmelerin, çevre sorunlarının insanlar üzerindeki etkilerinin azaltılmasına yönelik uygulamalara katkı sağlaması beklenmektedir.

\section{TEŞEKKÜR}

Bu çalışma Kahramanmaraş Sütçü İmam Üniversitesi Bilimsel Araştırma Projeleri Koordinasyon Birimi tarafindan 2017/2-59M nolu araştırma projesi kapsamında desteklenmiştir.

\section{KAYNAKLAR}

Akay, A., 2015. Kent İçi Alanlarda Trafik Gürültüsünün Bitki Kullanımı İle Kontrolü: Konyaİstanbul Çevre Yolu Örneği. Yüksek Lisans Tezi. Selçuk Üniversitesi Fen Bilimleri Enstitüsü, Konya.

Aktaş, Y., 2002. Kent İçi Alanlarda Bitki Kullanımı ile Gürültü Kontrolü (İstanbul, Maslak-Zincirlikuyu Hattı Örneğinde). Yüksek Lisans Tezi. İstanbul Üniversitesi Fen Bilimleri Enstitüsü, İstanbul.

Anonymous, 2009a. Ensuring quality of life in Europe's cities and towns: Tackling the environmental challenges driven by European and global change. European Environment Agency, Report no: 5/2009.

Anonymous, 2009b. HD2010 Integrating Sound Level Meter Spectrum Analyzer, Rev. 3.5, Delta OHM SRL, Italy, Pp. 160.

Bayramoğlu, E., Işık, Ö. B., Demirel, Ö., 2014. Gürültü Kirliliğinin Kent Parklarına Etkisi ve Çözüm Önerileri: Trabzon Kenti Örneği. İnönü Üniversitesi Sanat ve Tasarım Dergisi, 4, 9, 35-42.

Doygun, N., 2016. Analysing Traffic Noise on the Avsar Campus of the Kahramanmaras Sutcu Imam University. Inonu University Journal of Art and Design, 6(14), 1-11. DOI: 10.16950/iüstd.32311

Doygun, H., Gürün, D. K., 2008. Analysing and mapping spatial and temporal dynamics of urban traffic noise pollution: a case study in Kahramanmaraş, Turkey. Environmental Monitoring and Assessment, 142, 65-72.

Erdoğan, E., Yazgan, M., 2007. Kentlerde Trafik Gürültüsü Sorununu Azaltmada Peyzaj Mimarlığı Çalışmaları: Ankara Örneği. Tekirdağ Ziraat Fakültesi Dergisi. 4 (2), 201-210.

Kalansuriya, C. M., Pannila, A. S., Sonnadara, D. U. J., 2009. Effect of roadside vegetation on the reduction of traffic noise levels. Proceedings of the Technical Sessions, Institute of Physics - Sri Lanka, 25, 1-6.

Morova, N., Şener, E., Terzi, S., Beyhan, M., Harman, B. I., 2010. Süleyman Demirel Üniversitesi Yerleşkesinin Gürültü Haritalarının Coğrafi Bilgi 
Sistemleri ile Hazırlanması. Süleyman Demirel Üniversitesi, Fen Bilimleri Enstitüsü Dergisi, 143,271-278.

Mutlu, Z., 2010. Konya Kentiçi Trafik Gürültüsünün Engellenmesinde Kullanılacak Bazı Bitkiler Üzerinde Bir Araştırma. Yüksek Lisans Tezi, Selçuk Üniversitesi Fen Bilimleri Enstitüsü Peyzaj Mimarlığı Anabilim Dalı.

Önder, S., Koçbeker, Z., 2012. Importance of the Green Belts to Reduce Noise Pollution and Determination of Roadside Noise Reduction Effectiveness of Bushes in Konya. International Journal of Biological, Biomolecular, Agricultural, Food and Biotechnological Engineering. 6 (6), 373-376.

Özer, S., Irmak, M. A., Yılmaz, H., 2008. Determination of roadside noise reduction effectiveness of Pinus sylvestris L. and Populus nigra L. in Erzurum, Turkey. Environmental Monitoring and Assessment, 144:191-197.

Posada, M. I., Arroyave, M. P., Fernandez, C., 2009. Influencia de la Vegetación en los Niveles de Ruido Urbano. Revista Escuela de Ingeniería de Antioquia, 12, 79-89.

Renterghem, T., Botteldooren, D., 2016. View on outdoor vegetation reduces noise annoyance for dwellers near busy roads. Landscape and Urban Planning, 148, 203-215.
Stanners, D., Bourdeau, P. (Eds.), 1995. Europe's environment: the Dobris assessment. European Environment Agency, EC DG XI and Phare, Copenhagen, Denmark, 676 pp.

Ustasüleyman, T., 1998. Gürültü Sorunu ve Gürültünün Azaltılmasında Bitkisel Materyalin Kullanımı ile İlgili Ölçüm Yöntemleriyle Yapılmış Çalışmaların Derlenmesi. Yüksek Lisans Tezi. Karadeniz Teknik Üniversitesi Fen Bilimleri Enstitüsü, Trabzon.

WHO (World Health Organization), 2012. Methodological guidance for estimating the burden of disease from environmental noise. T. Hellmuth, T. Classen, R. Kimvand, S. Kephalopoulos (Eds.), WHO Regional Office for Europe, 69p.

Yeşil, M., Atabeyoğlu, Ö., Yeşil, P., 2015. Karayollarının kent içi trafik gürültüsü düzeyine etkisi: Ordu kent merkezi örneği. Turkish Journal of Forestry, 16(2): 177-182.

Zannin, P. H. T., Ferreira, A. M. C., Szemeretta, B., 2006. Evaluation of noise pollution in urban parks. Environmental Monitoring and Assessment, 118, 423-433.

Zannin, P. H. T., Engel, M. S., Fiedler, P. E. K., Bunn, F., 2013. Characterization of environmental noise based on noise measurements, noise mapping and interviews: A case study at a university campus in Brazil. Cities, 31, 317-327. 